\title{
Amifostine (WR-2721), a cytoprotective agent during high-dose cyclophosphamide treatment of non-Hodgkin's lymphomas: a phase II study
}

\section{C.A. De Souza ${ }^{1}$, G. Santini ${ }^{2}$, G. Marino2 ${ }^{2}$ S. Nati², A.M. Congiu ${ }^{2}$, A.C. Vigorito ${ }^{1}$ and $\mathrm{E}$. Damasio ${ }^{2}$}

\author{
${ }^{1}$ Centro de Hematologia e Hemoterapia, U nidade de Transplante de Medula, \\ Universidade Estadual de Campinas, Campinas, SP, Brasil \\ ${ }^{2}$ Department of Hematology, San M artino H ospital, Genoa, Italy
}

\section{Correspondence \\ C.A. De Souza \\ Centro de Hematologia e \\ Hemoterapia \\ Unidade de Transplante de Medula UNICAMP \\ 13083-080 Campinas, SP \\ Brasil \\ Fax: + 55-19-788-8750 \\ E-mail: carmino@obelix.unicamp.br \\ Publication supported by FAPESP}

Received August 10, 1999

Accepted March 9, 2000

\section{Abstract}

Clinical trials indicate that amifostine may confer protection on various normal tissues without attenuating anti-tumor response. When administered prior to chemotherapy or radiotherapy, it may provide a broad spectrum of cytoprotection including against alkylating drugs. The mechanism of protection resides in the metabolism at normal tissue site by membrane-bound alkaline phosphatase. Toxicity of this drug is moderate with hypotension, nausea and vomiting, and hypocalcemia being observed. We report a phase II study using amifostine as a protective drug against high-dose cyclophosphamide (HDCY) (7 $\mathrm{g} / \mathrm{m}^{2}$ ), used to mobilize peripheral blood progenitor cells (PBPC) and to reduce tumor burden. We enrolled 29 patients, 22 (75.9\%) affected by aggressive and $7(24.1 \%)$ by indolent non-Hodgkin's lymphoma (NHL), who were submitted to 58 infusions of amifostine and compared them with a historical group (33 patients) affected by aggressive NHL and treated with VACOP-B followed by HDCY. The most important results in favor of amifostine were the reduction of intensity of cardiac, pulmonary and hepatic toxicity, and a significant reduction of frequency and severity of mucositis $(\mathrm{P}=0.04)$. None of the 29 patients died in the protected group, while in the historical group 2/33 patients died because of cardiac or pulmonary toxicity and 2 patients stopped therapy due to toxicity. Amifostine did not prevent the aplastic phase following HDCY. PBPC collection and hematological recovery were adequate in both groups. The number of CFU-GM (colony-forming units-granulocyte/macrophage) colonies and mononuclear cells in the apheresis products was significantly higher in the amifostine group $(\mathrm{P}=0.02$ and 0.01 , respectively). Side effects were mild and easily controlled. We conclude that amifostine protection should be useful in HDCY to protect normal tissues, with acceptable side effects.
Key words

- Amifostine

- Cytoprotection

- Non-Hodgkin's lymphoma

- High-dose cyclophosphamide

- Peripheral blood progenitor cell mobilization 


\section{Introduction}

The two major obstacles in an effective cancer therapy are drug resistance and toxicity to normal organs which prevent the use of optimal doses and schedules. A broad-spectrum selective cytoprotective agent which improves patient tolerance could allow the delivery of higher cumulative doses of chemotherapy and would improve life quality, a useful adjunct in cancer medicine.

Amifostine is a pro-drug that is dephosphorylated in the tissue by alkaline phosphatase to a free thiol, the active metabolite (WR-1065) (1-3). It acts as a potent scavenger of oxygen free radicals induced by ionising radiation and certain types of chemotherapy (1-3). The mechanism of protection is based on physiological differences between the two tissue types and on differential uptake of amifostine in normal and tumor tissue (4). Cytoprotection has been found to correlate only with intracellular levels of the thiol metabolite WR-1065 (2). Further reaction with other intracellular thiol groups forms either its symmetrical disulfide or mixed disulfides. The hydrogen atom donation from these metabolites facilitates direct chemical repair at sites of DNA damage. Amifostine selectively protects a broad range of normal tissues against the toxicity associated with chemotherapy and radiation without affecting the anti-tumor activity of the agents (3,5-7). Many experiments have demonstrated that there is no evidence of attenuation of the anti-tumor effect when amifostine protection is used $(1,8,9)$. Preincubation with amifostine or WR-1065 enhanced the colony-forming capacity of the bone marrow progenitors, increasing recovery of CFU-GEMM (colony-forming unitsgranulocyte/erythroid/macrophage/megakaryocytic) and BFU-E (burst-forming unitserythroid) up to seven-fold $(1,10)$. Significant side effects related to amifostine include nausea, vomiting, and hypotension $(1,11,12)$. An additional side effect is tran- sient hypocalcemia because of inhibition of the release of parathyroid hormone $(1,13)$. The most clinically significant and doselimiting toxicity is hypotension generally at the end of the infusion and quickly reversible by discontinuation of the drug $(1,11,12)$. The precise mechanism of hypotension is unclear but it seems to be related to a direct vasodilator (14).

In view of these considerations, we report here a phase II study using amifostine protection in patients treated with high-dose alkylating agent (cyclophosphamide (CY), 7 $\mathrm{g} / \mathrm{m}^{2}$ ), in order to mobilize peripheral blood progenitor cells (PBPC) and to reduce the tumor mass in patients affected by nonHodgkin's lymphomas (NHL). The objective of the present investigation was to study the feasibility, side effects, and the extent of tissue and organ protection by amifostine.

\section{Patients and Methods}

From February 1997 to June 1999, 29 patients (14 males and 15 females), median age 46 years (range 18-56), 22 (75.9\%) affected by aggressive NHL and 7 (24.1\%) by indolent NHL, were enrolled in the study. Seven of the 29 patients $(24.1 \%)$ were in complete remission, $15(51.8 \%)$ in partial remission, and $7(24.1 \%)$ were non-responders. Twelve (41.3\%) patients had previously received one line of chemotherapy; 11 (37.9\%), two lines, and 6 (20.8\%), three or more (median treatment, 2 chemotherapy lines; range 1-5). The 29 patients were submitted to a total of $58 \mathrm{CY}$ infusions protected by amifostine during the progenitor cell mobilization procedure (15). The total CY dose $\left(7 \mathrm{~g} / \mathrm{m}^{2}\right)$ was divided into 5 equal infusions $\left(1.4 \mathrm{~g} / \mathrm{m}^{2}\right)$. Amifostine was infused $30 \mathrm{~min}$ before the first and 5th CY infusion, as shown in Table 1. Amifostine was infused for 15 min and CY was administered 15 min after the end of amifostine infusion. Urinary $\mathrm{pH}$ was determined before amifostine infusion and it had to be $\geq 7.0$. Patients presenting $\mathrm{pH}$ 
$<7$ were treated with sodium bicarbonate in order to achieve the ideal $\mathrm{pH}$ before infusion. Twenty-seven $(93.1 \%)$ patients were protected with $740 \mathrm{mg} / \mathrm{m}^{2}$ amifostine twice, while only two (6.9\%) patients received 910 $\mathrm{mg} / \mathrm{m}^{2}$ in each of the two infusions. Echocardiography was used as the criterion for the procedure. Patients presenting ventricular ejection fraction below $60 \%$ did not undergo therapy and patients presenting limit values were submitted to scintigraphy prior to highdose cyclophosphamide (HDCY).

We analyzed neutrophil and platelet recovery, median number and range of leukaphereses, total mononuclear cells, CD34 ${ }^{+}$cells and CFU-GM colonies obtained from leukapheresis products. CD34 cells were quantified using a modification of the method described by Sutherland et al. (16). In this modification, the CD14/FITC antibody was used instead of CD45 to exclude contamination with myeloid/monocytic cells of the CD34/PE-positive population defined as $\mathrm{CD} 14$ negative and presenting a low relative granularity or internal complexity. The in vitro colony-forming assay was performed by plating total unstimulated peripheral blood leukocytes obtained after red blood cell sedimentation in the presence of 33\% Emagel, as described elsewhere (17). The total number of CD34+ cells (x 106/kg) and CFU-GM (x $\left.10^{4} / \mathrm{kg}\right)$ was determined by multiplying their frequency per ml by the total volume of cryopreserved cell suspension and dividing by body weight. We compared these results with a historical non-protected group consisting of 40 patients affected by aggressive NHL. Before receiving HDCY, these patients were treated with a median number of 8 courses of VACOP-B (18), and 33 patients underwent HDCY therapy followed by granulocyte colony-stimulating factor (G-CSF) in order to collect PBPC and reduce the tumor burden. Seven patients did not undergo HDCY due to early death or progression of the disease. Table 2 shows the patients' characteristics, and Table 1 shows the time schedule for HDCY administration.
Table 1 - Time schedule for the administration of high-dose cyclophosphamide $\left(7 \mathrm{~g} / \mathrm{m}^{2}\right)$ and amifostine protection.

Hyperhydration plus furosemide and acetazolamide was used as previous support therapy. The standard dose of amifostine was $740 \mathrm{mg} / \mathrm{m}^{2}$. A dose of $910 \mathrm{mg} / \mathrm{m}^{2}$ was used in high-risk patients.

\begin{tabular}{|c|c|c|}
\hline Time (h) & Cyclophosphamide & Uromitexan \\
\hline & Amifostine (15 min) & \\
\hline 0 & $1.4 \mathrm{~g}\left(\mathrm{~m}^{2}\right)^{-1} \mathrm{~h}^{-1}$ & \\
\hline 1 & & $1.5 \mathrm{~g}\left(\mathrm{~m}^{2}\right)^{-1} \mathrm{~h}^{-1}$ \\
\hline 3 & $1.4 \mathrm{~g}\left(\mathrm{~m}^{2}\right)^{-1} \mathrm{~h}^{-1}$ & \\
\hline 4 & & $1.5 \mathrm{~g}\left(\mathrm{~m}^{2}\right)^{-1} \mathrm{~h}^{-1}$ \\
\hline 6 & $1.4 \mathrm{~g}\left(\mathrm{~m}^{2}\right)^{-1} \mathrm{~h}^{-1}$ & \\
\hline 7 & & $1.5 \mathrm{~g}\left(\mathrm{~m}^{2}\right)^{-1} \mathrm{~h}^{-1}$ \\
\hline 9 & $1.4 \mathrm{~g}\left(\mathrm{~m}^{2}\right)^{-1} \mathrm{~h}^{-1}$ & \\
\hline 10 & & 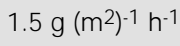 \\
\hline & Amifostine (15 min) & \\
\hline 12 & 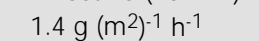 & \\
\hline 13 & & $1.5 \mathrm{~g}\left(\mathrm{~m}^{2}\right)^{-1} \mathrm{~h}^{-1}$ \\
\hline
\end{tabular}

Table 2 - Characteristics of the patients studied.

HDCY, High-dose cyclophosphamide.

\begin{tabular}{|c|c|c|}
\hline & No. & $\%$ \\
\hline \multicolumn{3}{|l|}{ Protected group } \\
\hline Number of patients & 29 & \\
\hline Age (year), median (range) & $46(18-56)$ & \\
\hline Male/female & $14 / 15$ & \\
\hline \multicolumn{3}{|l|}{ Histology } \\
\hline Aggressive non-Hodgkin's lymphoma & 22 & 75.9 \\
\hline Indolent non-Hodgkin's lymphoma & 7 & 24.1 \\
\hline \multicolumn{3}{|l|}{ Disease status } \\
\hline Partial remission & 15 & 51.8 \\
\hline Complete remission & 7 & 24.1 \\
\hline Non-responders & 7 & 24.1 \\
\hline \multicolumn{3}{|l|}{ Previous chemotherapy line } \\
\hline 1 & 12 & 41.3 \\
\hline 2 & 11 & 37.9 \\
\hline 3 or more & 6 & 20.8 \\
\hline Median (range) & $2(1-5)$ & \\
\hline \multicolumn{3}{|l|}{ Historical group } \\
\hline Number of patients at diagnosis & 40 & \\
\hline Age (year), median (range) & $51(20-60)$ & \\
\hline Male/female & $25 / 15$ & \\
\hline Histology - aggressive non-Hodgkin's lymphoma & 40 & 100 \\
\hline HDCY (after 8 cycles of VACOP-B) & 33 & 82.5 \\
\hline
\end{tabular}




\section{Side effects related to amifostine and evaluation of toxicity}

The most important short-term side effects of amifostine were the presence of nausea and/or vomiting, hypotension, hypocalcemia and flu-like symptoms. Blood pressure was determined each 5 min during amifostine infusion. The infusion was reduced when the systolic blood pressure decreased more than $10 \%$ or if it decreased $>20 \mathrm{mmHg}$ over a period of $5 \mathrm{~min}$ or if symptomatic hypotension was present. Serum calcium levels were determined before, during and after amifostine infusion and at 24-h intervals for 4 days. The side effects were treated using methylprednisolone and/or intravenous calcium injections. Thirteen patients were treated preventively with dexamethasone (20 mg, twice a day), intravenous calcium injection and glanisentron ( $3 \mathrm{mg}, i v)$ about $90 \mathrm{~min}$ before

Table 3 - Toxicity related to HDCY therapy in patients protected or not with amifostine (WHO classification).

HDCY, High-dose cyclophosphamide; NS, nonsignificant. Data were analyzed by the Fisher exact test.

\begin{tabular}{|c|c|c|c|c|c|c|c|c|c|c|c|c|c|}
\hline \multirow[t]{2}{*}{ Tissue/organ } & \multicolumn{6}{|c|}{$\begin{array}{l}\mathrm{HDCY}+\text { amifostine } \\
\text { grades - WHO }\end{array}$} & \multicolumn{6}{|c|}{$\begin{array}{c}\text { HDCY } \\
\text { grades - WHO }\end{array}$} & \multirow[t]{2}{*}{$\mathrm{P}$} \\
\hline & 0 & 1 & 2 & 3 & 4 & Total & 0 & 1 & 2 & 3 & 4 & Total & \\
\hline Heart & 27 & 1 & 1 & - & - & 29 & 31 & - & - & 1 & 1 & 33 & NS \\
\hline Liver & 28 & - & 1 & - & - & 29 & 29 & 2 & 1 & 1 & - & 33 & NS \\
\hline Mucositis & 28 & 1 & - & - & - & 29 & 26 & 4 & 2 & 1 & - & 33 & 0.04 \\
\hline Lung & 29 & - & - & - & - & 29 & 32 & - & - & - & 1 & 33 & NS \\
\hline Kidney & 29 & - & - & - & - & 29 & 30 & - & 1 & 1 & 1 & 33 & NS \\
\hline
\end{tabular}

Figure 1 - Blood pressure rate following amifostine infusion.

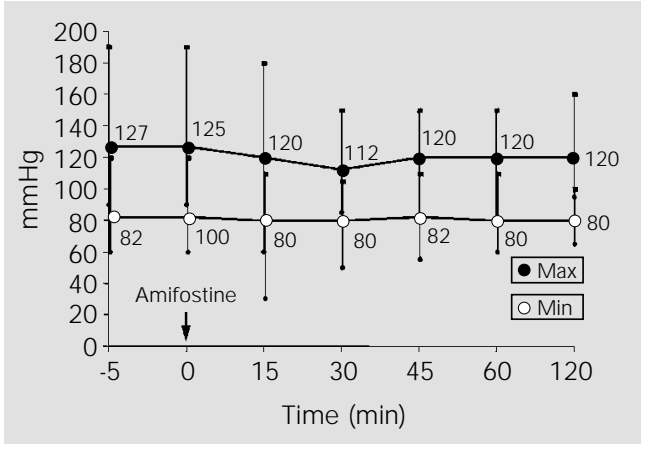

amifostine infusion. HDCY toxicity was determined according to the World Health Organization (WHO). Informed consent was obtained from the patients according to institution regulations.

\section{Statistical analysis}

Analysis was based on data for the amifostine group versus the historical non-protected group. Our main objective was to compare the theoretical benefits of amifostine cytoprotection. All data were analyzed with descriptive statistical methods and the proportions of patients within each group of characteristics and outcome, including shortterm side effects, were compared by the Fisher test. In addition, comparisons of the continuous variables were performed by the Mann-Whitney test, with the level of significance set at $\mathrm{P}<0.05$.

\section{Results}

\section{Amifostine-protected group}

The most important symptoms related to amifostine infusions were nausea and vomiting in $12 / 58$ patients (20.6\%), hypotension in $26 / 58$ (44.8\%), hypocalcemia in $4 / 58$ (6.9\%), and flu-like symptoms in 2/58 (3.5\%). All symptoms were mild and easily controlled by the use of methylprednisolone $(125 \mathrm{mg}, i v)$ or calcium gluconate $(100-300$ $\mathrm{mg}$, iv) when necessary. Twenty-three patients $(79 \%)$ presented fever of undetermined origin which was controlled with antibiotics. One patient presented grade 1 mucositis, two patients presented line contamination by Staphylococcus aureus, controlled with vancomycin, and one patient died due to progressive disease. Two patients showed cardiac toxicity, grade 1 and grade 2 , respectively. No severe toxicity (grades 3 and 4) was observed in liver, kidney or lung (Table 3). Regarding hypotension, Figure 1 shows a slight reduction in blood pressure (median 
reduction of about $7.5 \%$ ), 15 to $30 \mathrm{~min}$ after the beginning of amifostine infusion. No infusions were stopped because of hypotension. Figure 2 shows a slight reduction in serum calcium $72 \mathrm{~h}$ after amifostine infusion (median reduction of about $6 \%$ ). The median day for neutrophil counts above $0.5 \mathrm{x}$ $10^{9} / 1$ was the 12th (10th-18th), for counts $>1.0 \times 10^{9} / 1$ it was the 13th (10th-19th), for platelets $>20 \times 10^{9} / 1$ it was the 11th (9th25 th) and for platelets $>50 \times 10^{9} / 1$ it was the 12th (9th-30th). The median number of aphereses was 2 (range 1-9), the median total mononuclear cell count was $8.26 \times 10^{8} /$ $\mathrm{kg}$ (3.3-29.9), the median count of CD34+ cells was $12.35 \times 10^{6} / \mathrm{kg}(2.0-74.1)$, and the median number of CFU-GM colonies was $114.14 \times 10^{4} / \mathrm{kg}(27.7-680.0)$.

\section{Historical group}

Forty patients with aggressive NHL were enrolled in the study and received a median of 8 cycles of VACOP-B as front line therapy. Seven patients did not undergo HDCY due to progression of the disease or early death. Thirtythree patients underwent HDCY without amifostine protection. Four patients did not undergo autologous bone marrow transplantation due to severe toxicity after HDCY. Two patients died, one due to cardiac failure and one due to pulmonary fibrosis. In addition, two patients had severe liver and kidney toxicity, grades 3 and 4 , respectively. Table 3 shows the toxicity related to HDCY in this group. The median day for neutrophil counts above $0.5 \mathrm{x}$ $109 / 1$ was the 10 th $(7$ th- 17 th), for counts $>1.0$ $\mathrm{x} 10^{9} / \mathrm{l}$ it was the 10th (8th-21st), for platelets $>20 \times 10^{9} / 1$ it was the 11 th (7th-27th), and for platelets $>50 \times 10^{9} / \mathrm{l}$ it was the 13 th (8th-43th). Patients underwent leukapheresis on median day 12 (range 10-16). A median of 3 aphereses (range 1-7) was performed. The median number of harvested mononuclear cells was $6.10 \mathrm{x}$ $10^{8} / \mathrm{kg}$ (range 0.14-23.9), the median number of $\mathrm{CD}^{2} 4^{+}$cells was $17.08 \times 10^{6} / \mathrm{kg}$ (range 2.87-103.0), and the median number of CFU-
GM colonies was $45.0 \times 10^{4} / \mathrm{kg}$ (range 1.16681.0).

\section{Comparison between two groups}

Table 3 shows non-hematologic toxicity according to WHO grades in both groups analyzed and its statistical significance. $\mathrm{Mu}$ cositis toxicity was more frequent in the non-protected group $(\mathrm{P}=0.04)$. However, the most important clinical differences were observed in the severity of toxicity. In the historical group we observed severe cardiac, renal, hepatic and pulmonary toxicity, including two lethal cases. No differences in hematologic toxicity were observed between groups. Neutrophil recovery was faster in the historical group $(\mathrm{P}<0.001)$, while no difference was observed between groups in terms of platelet recovery. PBPC collections were similar in both groups in terms of CD $34^{+}$ cell numbers. However, the number of CFUGM colonies and mononuclear cells was significantly higher in the amifostine-protected group $(\mathrm{P}=0.02$ and $\mathrm{P}=0.01$, respectively). The median number of aphereses was 3 (1-9) in the historical group and 2 (17) in the amifostine group, showing a trend in favor of the amifostine group $(\mathrm{P}=0.06)$. Table 4 shows the biological data concerning PBPC mobilization in both groups.

\section{Discussion}

This phase II study using amifostine as a cytoprotective agent following an infusion

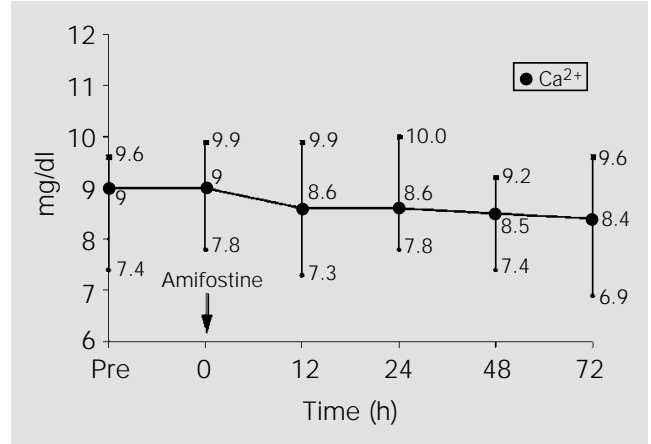

Figure 2 - Serum calcemia following amifostine infusion. 
of $7 \mathrm{~g} / \mathrm{m}^{2}$ of cyclophosphamide indicates that amifostine and its free thiol derivative may confer protection on most tissues and organs against HDCY. Amifostine was able to prevent severe and lethal cardiac and pulmonary toxicity, and to reduce the frequency and severity of renal toxicity and mucositis. Many antineoplastic drugs have been studied using cytoprotective agents including the anthracyclines, daunorubicin and doxorubicin, the anthracenedione, mitoxanthrone, paclitaxel, diaziquone, cisplatin, and thiotepa (1). However, few studies have used highdose alkylating drug protection in bone marrow transplantation and/or mobilization procedures (19). A one-way crossover phase II trial was conducted in order to evaluate the protective effect of amifostine against cyclophosphamide-induced hematologic toxicity (20). The patients received $1500 \mathrm{mg} / \mathrm{m}^{2}$ of CY alone, protected with $740 \mathrm{mg} / \mathrm{m}^{2}$ of amifostine. Amifostine significantly attenuated the neutrophil nadir $(\mathrm{P}<0.001)$ and reduced the duration of neutropenia grade 4 $(\mathrm{P} \leq 0.016)$. However, the $\mathrm{CY}$ dosage was much lower than those used in our study, and organic toxicity was not evaluated. On the other hand, our study using $7 \mathrm{~g} / \mathrm{m}^{2} \mathrm{CY}$ did not present any advantage of hematologic protection in terms of hematologic recovery compared with the historical group. The num- ber of CFU-GM and mononuclear cells, however, was significantly higher in spite of more chemotherapy cycles previously applied to most of the protected patients, suggesting amifostine protection of progenitor cells. In addition, we observed a trend in favor of the amifostine group in terms of number of aphereses, which was lower in the protected group $(\mathrm{P}=0.06)$. An important difference in favor of amifostine protection was the reduction of severe non-hematologic toxicity, particularly renal, hepatic, pulmonary and cardiac toxicity. Besides, mucositis was observed only in one patient (grade 1) and no treatment-related death was observed in the protected group. The choice of the protective dosage of amifostine used in this study was defined previously $(21,22)$, ranging from 740 to $910 \mathrm{mg} / \mathrm{m}^{2}$, and seems to be safe and to have low side effects. The side effects related to amifostine were mild and easily controlled. In 58 infusions, the most important side effects were nausea and vomiting, hypotension, and clinical and/or laboratory hypocalcemia. Nausea and vomiting should be treated with careful fluid balance monitoring, beginning before infusion and using anti-emetic medication prior to and in conjunction with amifostine. Hypotension may be controlled using hydration prior to amifostine infusion, maintaining

Table 4 - Biological data conceming the mobilization procedure using HDCY plus G-CSF in the amifostineprotected group and a historical non-protected group.

Data are reported as median (range) and were analyzed by the Mann-Whitney test. NS, Nonsignificant.

\begin{tabular}{lccc}
\hline & $\begin{array}{c}\text { Amifostine group } \\
\mathrm{N}=29\end{array}$ & $\begin{array}{c}\text { Historical group } \\
\mathrm{N}=33\end{array}$ & $\mathrm{P}$ \\
\hline Days - neutrophils $>0.5 \times 10^{9} / 1$ & $12(10-18)$ & $10(7-17)$ & $<0.0001$ \\
Days - neutrophils $>1.0 \times 10^{9} / 1$ & $13(10-19)$ & $10(8-21)$ & $<0.0001$ \\
Days - platelets $>20 \times 10^{9} / 1$ & $11(9-25)$ & $11(7-27)$ & $\mathrm{NS}$ \\
Days - platelets $>50 \times 10^{9} / 1$ & $12(9-30)$ & $13(8-43)$ & $\mathrm{NS}$ \\
Number of aphereses median (range) & $2(1-9)$ & $3(1-7)$ & 0.06 \\
Mononuclear cells $\times 10^{8} / \mathrm{kg}$ median (range) & $8.26(3.3-29.9)$ & $6.10(0.14-23.9)$ & 0.01 \\
CD34 ${ }^{+}$cells $\times 10^{6} / \mathrm{kg}$ median (range) & $12.35(2.0-74.1)$ & $17.08(2.87-103.0)$ & $\mathrm{NS}$ \\
CFU-GM $\times 10^{4} / \mathrm{kg}$ median (range) & $114.14(27.7-680.0)$ & $45.0(1.16-681.0)$ & 0.02 \\
& & &
\end{tabular}


patients in the supine position, and controlling their blood pressure every $5 \mathrm{~min}$. Calcium level was the only parameter that needed daily control for four to five days after amifostine infusion.

The administration of amifostine as a cytoprotective drug against HDCY seems to be simple and to have an acceptable toxicity profile. There was no evidence of attenuation of the anti-tumor effects in many experiments performed $(8,9)$. Careful patient selection, prophylactic therapy before amifostine and monitoring blood pressure during infusion can minimize some of the associated side effects. Further investigation of the cytoprotective effects of amifostine with high-dose alkylating chemotherapy, particularly HDCY in combination with growth factors, and its utility in the therapy and progenitor cell mobilization procedure is required to confirm the importance of this procedure for tissue and organ protection. Randomized trials, including cost-benefits analysis, are needed to demonstrate the clinical usefulness of amifostine in HDCY treatment.

\section{Acknowledgments}

We thank Eliana C.M. Miranda for data management.

\section{References}

1. List AF, Heaton R, Glinsmann-Gibson B \& Capizzi RL (1996). Amifostine protects primitive hematopoietic progenitors against chemotherapy cytotoxicity. Seminars in Oncology, 23 (Suppl 8): 58-63.

2. Smoluk GD, Fahey RC, Calabro-J ones PM, Aguilera J A \& Ward J F (1988). Radio-protection of cells in culture by WR-2721 and derivates: Form of the drug responsible for protection. Cancer Research, 48: 3641-3647.

3. Calabro-J ones PM, Agulera J A, Ward J F, Smoluk GD \& Fahey RC (1988). Uptake of WR-2721 derivates by cells in culture: Identification of the transported form of the drug. Cancer Research, 48: 36343640.

4. Capizzi RL (1996). The preclinical basis for broad-spectrum selective cytoprotection of normal tissues from cytotoxic therapies by amifostine (Ethiol). European J ournal of Cancer, 32 (Suppl 4): S5-S16.

5. Grdina DJ \& Sigdestad CP (1989). Radiation protectors: The unexpected benefits. Drug, 20: 13-42.

6. Calabro-J ones PM, Fahey RC, Smoluk GD \& Ward JF (1985). Alkaline phosphatase promotes radioprotection and accumulation of WR-1065 in V79-171 cells incubated in medium containing WR-2721. Intemational J ournal of Radiation Biology, 47: 23-27.

7. Schuchter LM \& Glick J H (1993). The current status of WR-2721 (amifostine): A chemotherapy and radiation therapy pro- tector. Biology Therapy Cancer Updates, 3: 1-10.

8. Yuhas J M, Spellman JM, J ordan SW, Pardini MC, Afzal SMJ \& Culo F (1980). Treatment of tumors with the combination of WR-2721 and cisdichlorodiamineplatinum (II) or cyclophosphamide. British J oumal of Cancer, 42: 574-585.

9. Yuhas J M (1980). A more general role for WR-2721 in cancer therapy. British J ournal of Cancer, 41: 832-834.

10. Wasserman $T H$, Philips $T L$, Ross $G \&$ Kane LJ (1981). Differential protection against cytotoxic chemotherapeutic effects on bone marrow CFUs by WR-2721. Cancer Clinical Trials, 4: 3-6.

11. Bukowski RM (1996). Amifostine (Ethiol): Dosing, administration and patient management guidelines. European J ournal of Cancer, 32A (Suppl 4): S46-S49.

12. Schuchter LM (1996). Guidelines for the administration of amifostine. Seminars in Oncology, 23 (Suppl 8): 40-43.

13. Glover DJ , Riley L \& Carmichael K (1983). Hypocalcemia and inhibition of parathyroid homone secretion after administration of WR-2721 (a radioprotective and chemoprotective agent). New England J oumal of Medicine, 309: 1137-1141.

14. U.S. Bioscience (1992). A phase I study to determine whether Ethiol (WR-2721) is a vasodilator when infused into the brachial artery of healthy volunteers. ETH CLPH 1.

15. Gianni AM, Bregni M, Siena S, Brambilla C, Di Nicola M, Lombardi F, Gandola L,
Tarella C, Pileri A, Ravagnani F, Valagussa P, Bonadonna G, Stern A, Magni M \& Caracciolo D (1997). High-dose chemotherapy and autologous bone marrow transplantation compared with MACOP-B in aggressive B-cell lymphoma. New England J oumal of Medicine, 336: 1290-1297.

16. Sutherland DR, Keating A, Nayar R, Anania S \& Stewart AK (1994). Sensitive detection and enumeration of $\mathrm{CD}_{3} 4^{+}$cells in peripheral and cord blood by cytometry. Experimental Hematology, 22: 10031110.

17. Tarella C, Benedetti G, Caracciolo D, Castellino C, Cherasco C, Bondesan P, Omede P, Ruggieri D, Gianni M \& Pileri A (1995). Both early and committed haematopoietic progenitors are more frequent in peripheral blood than in bone marrow during mobilization induced by high-dose chemotherapy + G-CSF. British J ournal of Haematology, 91: 535-543.

18. O'Reilly SE, Hoskins $P$, Klimo $P \&$ Connors JM (1991). MACOP-B and VACOP-B in diffuse large cell lymphomas and MOPP/ ABV in Hodgkin's disease. Annals of Oncology, 2 (Suppl 1): 17-23.

19. Schering-Plough International (1994). Ethiol (Amifostine) for the Prevention of Chemotherapy-Induced Toxicity [Product Monograph]. Schering-Plough International, Kenilworth, NJ , 37-44.

20. Glover DJ , Glick J H, Weiler C, Hurowitz S \& Kligerman MM (1986). WR-2721 protects against the hematologic toxicity of 
cyclophosphamide: A controlled phase II trial. J ournal of Clinical Oncology, 4: 584588.

21. Glover DJ , Fox KR, Weiler C, Kligerman MM, Turrisi A \& Glick J H (1988). Clinical trials of WR-2721 prior to alkylating agent chemotherapy and radiotherapy. Pharmacology and Therapeutics, 39: 3-7.

22. Adamson PC, Balis $F M$, Belasco J E, Lange B, Berg SL \& Blaney SM (1995). A phase I trial of amifostine (WR-2721) and melphalan in children with refractory cancer. Cancer Research, 55: 4069-4072. 